Check for updates

The BMJ

Cite this as: BMJ 2021;374:n2306 http://dx.doi.org/10.1136/bmj.n2306 Published: 20 September 2021

\title{
Covid-19: How is vaccination affecting hospital admissions and deaths?
}

\section{Gareth lacobucci}

\section{What do the data on hospital admissions show?}

An analysis of UK data from the National Immunisation Management Service (NIMS) and the Coronavirus Clinical Information Network (CO-CIN), ${ }^{1}$ endorsed by the UK Scientific and Advisory Group for Emergencies (SAGE), ${ }^{2}$ shows that of 40000 patients with covid-19 who were admitted to hospital between December 2020 and July 2021 a total of 33 $496(84 \%)$ had not been vaccinated. It found that $5198(13 \%)$ of these patients had received their first vaccine and $1274(3 \%)$ their second. A total of 611 patients with previous covid-19 (reinfection) were not included in the analysis.

\section{Is the picture similar for deaths?}

The important figure here is the number of "breakthrough" deaths, those involving covid-19 that occurred in someone who had received both vaccine doses and had a first positive PCR test result at least 14 days after the second vaccination dose. Data from the Office of National Statistics show that 256 (0.5\%) of the 51281 covid related deaths that occurred in England between 2 January and 2 July 2021 were breakthrough deaths. ${ }^{3}$ Nearly two thirds $(61.1 \%)$ of the breakthrough deaths were in men, whereas $52.2 \%$ of other covid-19 deaths were in men. And 13.1\% of breakthrough deaths were people who were identified from hospital episode data or causes of death as likely to have been immunocompromised, compared with $5.4 \%$ for other covid-19 deaths. SAGE noted this trend in its latest minutes, stating, "Vaccination generally reduced the odds of in-hospital mortality, although immunocompromised patients in the study had persistently high risk of mortality after both first and second dose vaccines." 4

\section{What effect have higher vaccination rates had on these trends?}

SAGE noted that most patients admitted to hospital with covid after 16 June 2021 were fully vaccinated. ${ }^{5}$ Public Health England said that even with a "highly effective vaccine" this was expected, given the high rate of vaccine uptake and a policy of vaccinating higher risk people first. In its latest surveillance report Public Health England emphasised that the rate of hospital admissions and death from covid remained "substantially greater" in unvaccinated than in vaccinated people. ${ }^{6}$ For example, between the week beginning Monday 16 August 2021 and the week ending Sunday 12 September, the rate of hospital admissions of over 80 was 50.5 per 100000 in the fully vaccinated and 143.9 per 100 ooo in the unvaccinated, while deaths were 45.5 and 145.4 per 100 ooo, respectively. These trends were seen across the board. For example, for 6o-69 year olds the hospital admission rates were 13.5 per 100 ooo in the fully vaccinated and 74.3 per 100 ooo in the unvaccinated, while deaths were 4.1 and 24.3 per 100 ooo, respectively.

\section{Which patient groups are most at risk after vaccination?}

In a paper published by The $B M J,{ }^{7}$ researchers from the University of Oxford reported on their updated QCovid tool, which identifies vaccinated people who are at greatest risk of severe covid-19 leading to hospital admission or death from 14 days after their second dose. It highlighted an elevated risk among people who are immunosuppressed as a result of chemotherapy, a recent bone marrow or solid organ transplantation, or HIV and AIDS; people with neurological disorders, including dementia and Parkinson's; care home residents; and people with chronic disorders, including Down's syndrome. Julia Hippisley-Cox, professor of clinical epidemiology and general practice at Oxford and coauthor of the paper, said that the tool could be used to help identify patients at highest risk of serious outcomes despite vaccination for targeted intervention, and to "inform discussions between doctors and patients about the level of risk to aid shared decision making."

Egan C, Thorpe M, Knight S, et al. Hospital admission for covid-19 and impact of vaccination: analysis of linked data from the National Immunisation Management Service (NIMS) and the Coronavirus Clinical Information Network (CO-CIN). https://assets.publishing.service.gov.uk/government/uploads/system/uploads/attachment_data/file/1018555/S1363_Hospital_Ad mission_for_COVID-19_and_impact_of_vaccination.pdf.

2 CO-CIN. Hospital admission for COVID-19 and impact of vaccination, 9 September 2021. Sep 2021. https://www.gov.uk/government/publications/co-cin-hospital-admission-for-covid-19-and-impact-of-vaccination-9 september-2021.

3 Office for National Statistics. Deaths involving covid-19 by vaccination status, England: deaths occurring between 2 January and 2 July 2021. Sep 2021. https://www.ons.gov.uk/peoplepopulationandcommunity/birthsdeathsandmarriages/deaths/articles/deathsinvolvingcovid19byvaccinationstatusengland/deathsoccurringbetween2januaryand2july2021.

4 CO-CIN. Hospital admission for COVID-19 and impact of vaccination, 9 September 2021. Sep 2021. https://www.gov.uk/government/publications/co-cin-hospital-admission-for-covid-19-and-impact-of-vaccination-9september-2021.

5 SAGE. Ninety-fifth SAGE meeting on COVID-19, 09 September 2021. Sep 2021. https://assets.publishing.service.gov.uk/government/uploads/system/uploads/attachment_data/file/1017296/S1360_SAGE_95_minutes.pdf.

$6 \quad$ Public Health England. Covid-19 vaccine surveillance report week 37. https://assets.publishing.service.gov.uk/government/uploads/system/uploads/attachment_data/file/1018416/Vaccine_surveillance_report__week_37_v2.pdf.

7 Hippisley-Cox J, Coupland CAC, Mehta N, etal. Risk prediction of covid-19 related death and hospital admission in adults after covid-19 vaccination: national prospective cohort study. BMJ2021;374:n2244. doi: 10.1136/bmj.n2244 pmid: 34535466

This article is made freely available for use in accordance with BMJ's website terms and conditions for the duration of the covid-19 pandemic or until otherwise determined by BMJ. You may use, download and print the article for any lawful, non-commercial purpose (including text and data mining) provided that all copyright notices and trade marks are retained. 